\title{
Haemodynamic effects of hypotension induced by KRN2391 and nicardipine in isoflurane anaesthetized dogs
}

Shohei Takeda $M D$,
Yoshiki Ozawa $M D$,
Teruaki Tomaru MD

Purpose: The investigational agent, KRN2391, is a potassium channel opener with a nitrate moiety which possesses potent vasodilatory action. We compared the haemodynamic effects of KRN2391-induced hypotension with those of nicardipine.

Methods: Sixteen dogs were anaesthetized with isoflurane $1.3 \%$ in oxygen (I MAC). After the baseline period, mean arterial pressure (MAP) was decreased to $60 \mathrm{~mm} \mathrm{Hg}$ for $60 \mathrm{~min}$ with an infusion of either $\operatorname{KRN} 2391(n=8)$ or nicardipine $(n=8)$.

Results: The KRN2391- and nicardipine-induced hypotension resulted in maximal decreased systemic vascular resistance of $35 \%$ and $25 \%$, increases in cardiac index of $145 \%$ and $197 \%$, and stroke volume index of $150 \%$ and $212 \%$, respectively, $(P<0.01)$. There was no change in heart rate. Nicardipine was associated with increases $(P<0.01)$ in both right atrial and mean pulmonary artery pressures, whereas these variables remained unchanged with KRN2391. Pulmonary capillary wedge pressure decreased with KRN239I $(P<0.01)$, but not with nicardipine.

Conclusion: While both drugs were equally able of inducing hypotension, our results show that the haemodynamic profile of KRN2391- and nicardipine-induced hypotension was a hypendynamic state expressed by the marked increase in cardiac index with varying changes in right and left ventricular filling pressures, and suggest that KRN239I may be a useful vasodilator for induced hypotension.

Objectif : Le KRN239I, un composé présentement à l'étude porteur d'une fraction moléculaire nitrate, exerce une activité vasodilatatrice puissante par ouverture des canaux potassiques. Nous avons comparé les effets hémodynamiques de l'hypotension induite par le KRN239 | avec ceux de la nicardipine.

Méthodes : Seize chiens ont été anesthésiés à l'isoflurane 1,3\% (I MAC). Après la période d'équilibration, la pression artérielle moyenne (PAM) a été réduite à $60 \mathrm{mmHg}$ avec une perfusion de KRN239/ $(n=8)$ ou de nicardipine $(n=8)$.

Résultats : L'hypotension induite par le KRN239 | et la nicardipine a fait baisser la résistance vasculaire systémique respectivement de $35 \%$ et $25 \%$, augmenter l'index cardiaque de $145 \%$ et $197 \%$ et la fraction d'ejection indexée de $150 \%$ et $212 \%(P<0,01)$. Par contre, la fréquence cardiaque n'a pas changé. La nicardipine était associée à des augmentations $(P<0,01)$ des pressions auriculaires droites et artérielles pulmonaires moyennes, alors que ces variables ne changeaient pas avec le KRN2391. La pression capillaire bloquée diminuait avec le KRN2391 $(P<0,01)$ mais pas avec la nicardipine.

Conclusion : Alors que les deux médicaments ont la même capacité d'induction hypotensive, nos résultats montrent que le profil hémodynamique de l'hypotension produite par le KRN239| et la nicardipine indique un état hyperdynamique qui se manifeste par une augmentation importante de l'index cardiaque et des changements variables des pressions de remplissage des ventricules droit et gauche. Ces résultats suggèrent aussi que le KRN2391 pourrait être utilisé pour induire l'hypotension délibérée.

From the Department of Anesthesiology, Showa University Fujigaoka Hospital, 1-30 Fujigaoka, Aoba-ku, Yokohama 227, Japan. Address correspondence to: Shohei Takeda MD, Phone: +81-45-971-1151; Fax: +81-45-973-1019.

This research presented in part at the 11th World Congress of Anaesthesiologists, Sydney, Australia, April 14-20, 1996 and was supported by a Grant from Showa University.

Accepted for publication June 15, 1997. 
$\mathrm{T}$

HE recently synthesized investigational hypotensive agent, KRN2391 [N-cyano-N'(2-nitroxyethyl)-3-pyridinecarboxamidine mono methanesulfonate], has antihypertensive and vasodilatory properties. The vasodilating mechanism of KRN2391 is thought to be based on its dual effects as a nitrate and a potassium channel opener. ${ }^{1,2}$ Further, it has been shown that KRN2391 possesses different vasorelaxant properties from those of cromakalim, nitroglycerin, and nifedipine. ${ }^{3}$

Intravenous administration of KRN2391 produced an increase in coronary blood flow and a decrease in mean arterial pressure in pentobarbital anaesthetized $\operatorname{dogs}^{4}$ and it is reported to produce an increase in oxygen supply to the heart and a decrease in oxygen consumption. ${ }^{5}$ We reported that KRN2391 decreases mean arterial pressure in a dose-dependent fashion by a reduction of systemic vascular resistance, and that KRN2391-induced reflex tachycardia may be suppressed by halothane anaesthesia in dogs. ${ }^{6}$ From these observations, the haemodynamic profile of KRN2391 may make it acceptable for induced hypotension during surgery with volatile anaesthetic agents.

Nicardipine is a calcium channel blocker that possesses potent systemic and coronary vasodilating activities. Its use is mainly for perioperative haemodynamic control such as systemic hypertension, vasospastic conditions, and myocardial protection. ${ }^{7}$ Recently, it has been reported that nicardipine-induced hypotension has been used in orthopaedic surgery using fentany $l^{8}$ and isoflurane anaesthesia. ${ }^{9}$

It is possible that different mechanisms of vasodilating activity are induced by KRN2391 and nicardipine, resulting in different systemic haemodynamic changes. The objectives of this study were to compare the haemodynamic effects of KRN2391 and nicardipine-induced hypotension.

\section{Methods}

All experimental procedures and the protocols for this study were approved by the Animal Experimental Ethics Committee of Showa University Fujigaoka Hospital. Sixteen healthy adult mongrel dogs of both sexes weighing between 12 and $18 \mathrm{~kg}(14.6 \pm 1.8 \mathrm{~kg}$, means $\pm S D)$ were fasted overnight and anaesthetized with sodium pentobarbital $\left(25 \mathrm{mg} \cdot \mathrm{kg}^{-1}\right) \mathrm{iv}$. After tracheal intubation, the lungs were mechanically ventilated with a Harvard respirator to maintain normocapnia. Anaesthesia was maintained with $1.0 \mathrm{MAC}$ isoflurane $(1.3 \%)$ via an Ohmeda Vaporizer (BOC Health Care, Windlesham, U.K.) using oxygen as a carrier gas at a flow rate of 3-5 $1 \cdot \mathrm{min}^{-1}$ throughout the experimental period. End-tidal isoflurane and $\mathrm{CO}_{2}$ concentrations were measured con- tinuously by an infrared analyzer (Capnomac Ultima, Datex, Helsinki, Finland).

\section{Instrumentation}

Cannulae were placed by a cutdown into the left femoral artery for continuous systemic blood pressure (SBP) monitoring and blood sampling, and into the right femoral vein for drug administration. Normal saline was infused at a rate of $7 \mathrm{ml} \cdot \mathrm{kg}^{-1} \cdot \mathrm{hr}^{-1}$ together with the infusion of the hypotensive drugs. A 7-F flowdirected pulmonary catheter (Swan-Ganz thermodilution catheter, Baxter Health Care, Irvine, U.S.A.) was advanced into a pulmonary artery via cutdown of the right external jugular vein and positioned by means of pressure monitoring in a branch of the pulmonary artery for the measurement of right atrial pressure (RAP), pulmonary artery pressure (PAP), pulmonary capillary wedge pressure (PCWP), and cardiac output (CO). The CO was measured in triplicate, by the thermodilution technique; we used a cardiac output computer (MTC6210, Nihon Kohden, Tokyo, Japan) and injected $5 \mathrm{ml}$ ice cold, temperature monitored, normal saline into the right atrium at end-expiration.

Heart rate (HR), was calculated from lead II of the ECG using a cardiotachometer (AT601G, Nihon Kohden), which was continuously monitored.

Each pressure monitoring catheter was connected to a pressure transducer (Uniflow, Baxter Health Care). Blood pressure and ECG were monitored continuously on a polygraph (RM6200, Nihon Kohden) and recorded with an eight-channel pen recorder (VM-640G, Nihon Kohden). The animals were fixed in the supine position during the measurements, and the zero reference was leveled at the midchest. Mean arterial pressure (MAP) and mean pulmonary artery pressure (MPAP) were determined electronically. Body temperature, monitored by a thermistor attached to the pulmonary artery catheter, was maintained at $37.0 \pm 1.0^{\circ} \mathrm{C}$ with electric heating pads and lamps. Cardiac index (CI), stroke volume index (SVI), systemic vascular resistance (SVR) and pulmonary vascular resistance (PVR) were calculated using standard formulae.

\section{Experimental protocol}

The 16 dogs were divided randomly into two groups: The KRN2391 group ( $n=8)$ received KRN2391, $0.02 \%$, and the nicardipine group $(\mathrm{n}=8)$ nicardipine, $0.2 \%$, dissolved in normal saline.

After completion of surgical preparations, the animals were observed for approximately $60 \mathrm{~min}$ to allow haemodynamic variables (SBP, MPAP, and HR) to stabilize. Measurements of baseline values were obtained before infusion of the hypotensive drugs. After base- 
line measurements had been made, MAP was reduced to $60 \mathrm{mmHg}$ for $60 \mathrm{~min}$ by infusion of KRN2391 or nicardipine. The solutions were infused into the left femoral vein with an infusion pump (Model STG-521, Terumo, Tokyo, Japan). Measurements of haemodynamic variables were taken 30 and $60 \mathrm{~min}$ after induction of hypotension, and 10 and $30 \mathrm{~min}$ after termination of drug infusion.

\section{Statistical analysis}

Values are expressed as mean \pm SD. Intragroup differences were analyzed by a two-way analysis of variance from repeated measurements of the same variables followed by Dunnett's test when appropriate. Intergroup differences of values in each of the phases (baseline, during and after induced hypotension) between the KRN2391 and nicardipine groups were analyzed by Student's unpaired $\mathrm{t}$ test if the $\mathrm{F}$ test was significant. A $P<0.05$ was considered statistically significant.

\section{Results}

There were no differences in baseline systemic haemodynamic values between the KRN2391 and nicardipine groups (Table I). The mean doses of KRN2391 and nicardipine required to maintain $\mathrm{MAP}$ at 60 $\mathrm{mmHg}$ for $60 \mathrm{~min}$ were $5.5 \pm 4.0 \mu \mathrm{g} \cdot \mathrm{kg}^{-1} \mathrm{~min}^{-1}$ and $18.3 \pm 10.2 \mu \mathrm{g} \cdot \mathrm{kg}^{-1} \cdot \mathrm{min}^{-1}$, respectively.

Mean arterial pressure decreased from baseline values of $109 \pm 13 \mathrm{mmHg}$ and $106 \pm 10 \mathrm{mmHg}$ in the KRN2391- and nicardipine groups to $60 \mathrm{mmHg}$ $(P<0.01)$ at $60 \mathrm{~min}$ of the hypotensive period, respectively. Within $30 \mathrm{~min}$ after termination of drug infusion, MAP gradually returned towards the base-

TABLE I Baseline values of MAP, CI, SVI, HR, SVR, PVR, RAP, MPAP, and PCWP in the KRN239l and nicardipine groups

\begin{tabular}{lll}
\hline & $\begin{array}{l}\text { KRN2391 } \\
(n=8)\end{array}$ & $\begin{array}{l}\text { Nicardipine } \\
(n=8)\end{array}$ \\
\hline MAP $(\mathrm{mmHg})$ & $109 \pm 13$ & $106 \pm 10$ \\
CI $\left(1 \cdot \mathrm{min}^{-1} \cdot \mathrm{m}^{-2}\right)$ & $2.9 \pm 0.5$ & $2.7 \pm 0.6$ \\
SVI $\left(\mathrm{ml} \cdot \mathrm{beats}^{-1} \cdot \mathrm{m}^{-2}\right)$ & $16 \pm 4$ & $17 \pm 5$ \\
HR (bpm) & $147 \pm 12$ & $149 \pm 9$ \\
SVR (dynes $\left.\cdot \mathrm{sec} \cdot \mathrm{cm}^{-5}\right)$ & $4158 \pm 901$ & $4700 \pm 1051$ \\
PVR (dynes $\left.\cdot \mathrm{sec} \cdot \mathrm{cm}^{-5}\right)$ & $271 \pm 44$ & $346 \pm 123$ \\
RAP (mmHg) & $4 \pm 1$ & $3 \pm 1$ \\
MPAP $(\mathrm{mmHg})$ & $16 \pm 3$ & $17 \pm 4$ \\
PCWP $(\mathrm{mmHg})$ & $8 \pm 1$ & $9 \pm 4$ \\
\hline
\end{tabular}

Values are means $\pm S D$

MAP $=$ mean arterial pressure $\mathrm{CI}=$ cardiac index $; \mathrm{SVI}=$ stroke volume index; $H R=$ heart rate $S \mathrm{SVR}=$ systemic vascular resistance; $\mathrm{PVR}=$ pulmonary vascular resistance; $\mathrm{RAP}=$ right atrial pressure; MPAP = mean pulmonary artery pressure; $\mathrm{PCWP}=$ pulmonary capillary wedge pressure line values but the values at $30 \mathrm{~min}$ were lower than baseline values in both groups (Figure 1, top). Cardiac index in the nicardipine group increased from baseline values of $2.7 \pm 0.61 \cdot \mathrm{min}^{-1} \cdot \mathrm{m}^{-2}$ to a maximum of $5.2 \pm 0.9(P<0.01) 1 \cdot \mathrm{min}^{-1} \cdot \mathrm{m}^{-2}$ at $60 \mathrm{~min}$ of the hypotensive period and plateaued at approximately $192 \%$ of baseline values for up to $30 \mathrm{~min}$ after termination of infusion. Cardiac index in the KRN2391 group increased from baseline values of $2.9 \pm 0.5$ $1 \cdot \mathrm{min}^{-1} \cdot \mathrm{m}^{-2}$ to a maximum of $4.2 \pm 0.9(P<0.01)$ $1 \cdot \mathrm{min}^{-1} \cdot \mathrm{m}^{-2}$ at $60 \mathrm{~min}$ of the hypotensive period and then gradually recovered to near baseline values by $\mathbf{3 0}$ min after termination of infusion (Figure 1 , middle). The changes in SVI were similar to the changes in CI during and after induced hypotension in both groups, respectively. Systemic vascular resistance in the KRN2391 group declined from baseline values of $4158 \pm 901$ dynes $\cdot \mathrm{sec} \cdot \mathrm{cm}^{-5}$ to a nadir of $1448 \pm 378$ $(P<0.01)$ dynes.sec $\cdot \mathrm{cm}^{-5}$ at $60 \mathrm{~min}$ followed by a reduction $(P<0.01)$ below the baseline values after termination of infusion. Systemic vascular resistance declined from baseline values of $4700 \pm 1051$ dynes.sec $\cdot \mathrm{cm}^{-5}$ to a nadir of $1253 \pm 313(P<0.01)$ dynes.sec. $\mathrm{cm}^{-5}$ at $60 \mathrm{~min}$ followed by a reduction $(P<0.01)$ below the baseline values after termination of infusion in the nicardipine group. Systemic vascular resistance was lower $(P<0.01)$ in the nicardipine group than in the KRN2391 group $30 \mathrm{~min}$ after induced hypotension was terminated (Figure 1, bottom). Pulmonary vascular resistance and HR did not change significantly throughout the course of observation in both groups, respectively. Right atrial pressure in the KRN2391 group remained unchanged throughout the course of observation. Right atrial pressure in the nicardipine group increased $(P<0.01)$ at $60 \mathrm{~min}$ followed by an increase $(P<0.01)$ after induced hypotension (Figure 2, top). The changes in MPAP were similar to the changes in patterns of RAP during and after induced hypotension in both groups, respectively (Figure 2 , middle). Pulmonary capillary wedge pressure in the KRN2391 group decreased $(P<0.01)$ during the hypotensive period followed by a decrease $10 \mathrm{~min}$ after termination of infusion. In contrast, PCWP in the nicardipine group did not change during and after induced hypotension. Pulmonary capillary wedge pressure was lower $(P<0.05)$ in the KRN239l group than in the nicardipine group at $60 \mathrm{~min}$ (Figure 2, bottom).

\section{Discussion}

The results of the present study demonstrated that the haemodynamic profiles of KRN2391- and nicardipineinduced hypotension produced a hyperdynamic state 

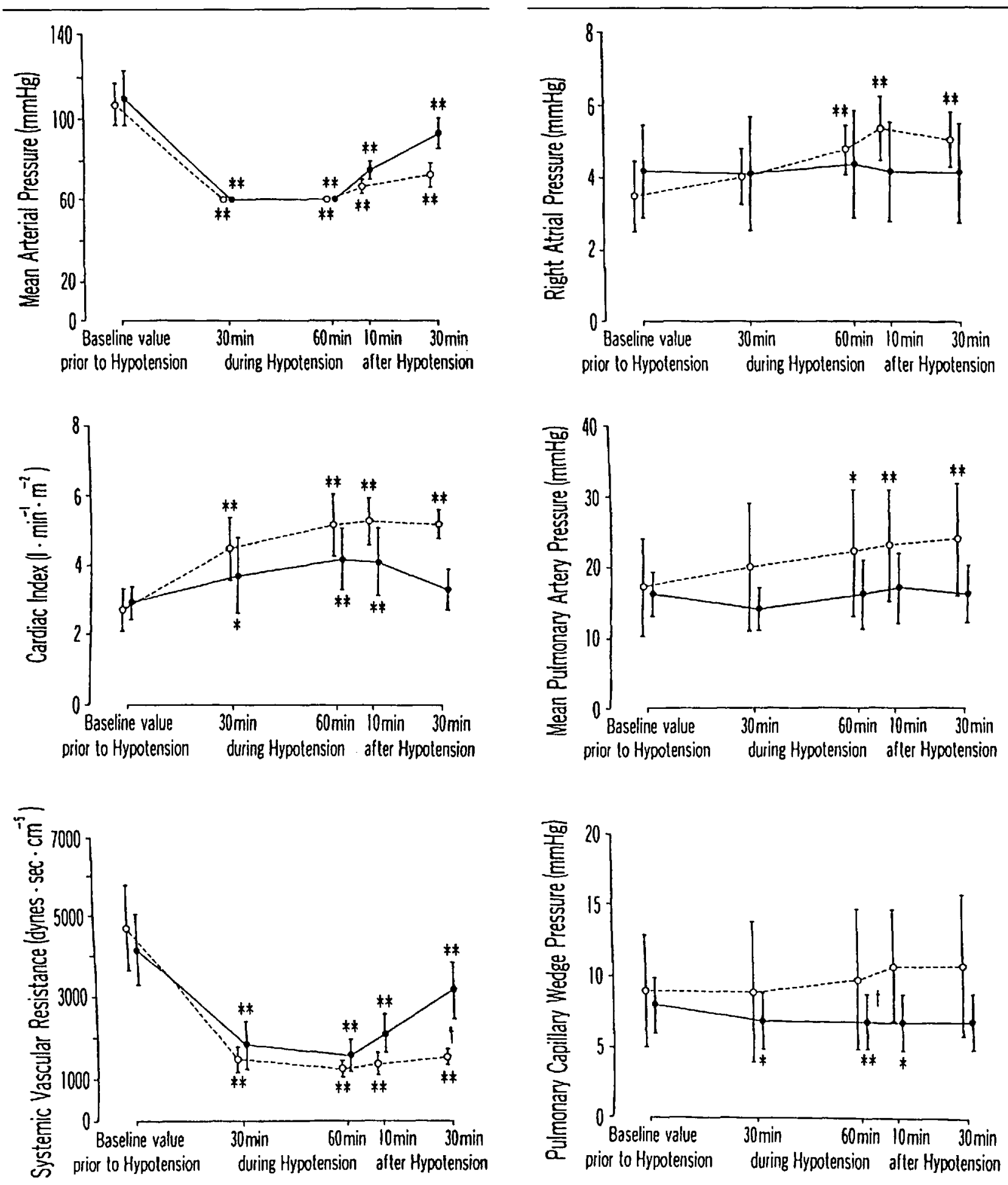

FIGURE I Effect of KRN239l ( $n=8$, solid circles) and nicardipine ( $n=8$, open circles)-induced hypotension on mean arterial pressure (top), cardiac index (middle), and systemic vascular resistance (bottom) in isoflurane anaesthetized dogs. * $P<0.05,{ }^{* *} P<0.01$ vs baseline $\dagger P<0.01$ different from KRN239l and nicardipine (These values were compared at predetermined identical times) Values are means $\pm \mathrm{SD}$

FIGURE 2 Effect of KRN2391 ( $\mathrm{n}=8$, solid circles) and nicardipine ( $n=8$, open circles)-induced hypotension on right atrial pressure (top), mean pulmonary artery pressure (middle), and pulmonary capillary wedge pressure (bottom) in isoflurane anaesthetized dogs. ${ }^{*} P<0.05, * * P<0.01$ vs baseline

${ }^{t} P<0.05$ different from KRN2391 and nicardipine (These values were compared at predetermined identical times) Values are means $\pm S D$ 
expressed by an increase in CI with varying change in right and left ventricular filling pressures.

Calcium channel blockers produce vasodilatory effects by blocking voltage-dependent transmembrane $\mathrm{Ca}^{2+}$ entry. The mechanism of potassium channel openers was thought to be similar to that of calcium channel blockers, because potassium channel openers hyperpolarize cell membranes and decrease $\mathrm{Ca}^{2+}$ influx through inhibition of the voltage-dependent $\mathrm{Ca}^{2+}$ channel. ${ }^{10}$ However, KRN2391 has dual vasodilating mechanisms due to both nitrate and potassium channel opening actions. ${ }^{1,2}$ Although potassium channel opening is considered to be the major mechanism of the vasodilating effect of $\mathrm{KRN} 2391$, activation of guanylate cyclase by KRN2391 is mediated in a manner characteristic of nitrovasodilators because of the presence of the nitrate moiety within its structure. ${ }^{1}$

The hypotension associated with both KRN239l and nicardipine was demonstrated to be profound vasodilation of the resistance vessels. However, neither drug dilated the capacitance vessels, because right ventricular filling pressures remained unchanged during KRN2391 infusion, while nicardipine increased these variables. The lack of venodilatation may have contributed to the increase in venous return. Concomitant with the lack of venodilatation, the reduction in afterload was responsible for the increase in $\mathrm{CI}$ in the present study. The marked increase in CI during KRN2391- or nicardipineinduced hypotension was in contrast to the haemodynamic profile of hypotension induced by sodium nitroprusside ${ }^{11}$ or nitroglycerin, ${ }^{12}$ which act on both the resistance and capacitance vessels, resulting in reduction of preload and afterload and a decrease in CI. Further, the increases in the right ventricular filling pressures with nicardipine were accompanied by an increase in left ventricular filling pressure. Right and left ventricular filling pressures did not increase during KRN2391 administration. Our results suggest that the difference of left ventricular filling pressure between KRN2391 and nicardipine may be due to the different responses related to KRN2391 and nicardipine caused by the varying sensitivity and density of the potassium channels or calcium channels in the pulmonary vasculature. In addition, the pulmonary vasculature dilatation may be due to the nitrate action caused by KRN2391. These differences between KRN2391 and nicardipine in their effects on capacitance vessels and pulmonary vasculature should be considered when these drugs are used clinically. Both KRN2391 and nicardipine may be beneficial in maintaining venous return and cardiac output, and can be used safely in patients with hypovolemia. In contrast, nicardipine should not be used in the presence of congestive heart failure and pulmonary hypertension because of the lack of venodilation or the overload of pulmonary vasculature. As a hyperdynamic state exists, reflex sympathetic activation may be elicited, leading to release of catecholamines. It has been reported that the hormonal effects of nicardipine-induced hypotension were provoked by the activation of the sympathetic nervous system. ${ }^{8,13,14}$ Another explanation for the present findings may be that the reflex sympathetic activation can oppose the effects of the vasodilating activity of KRN2391 or nicardipine on the venous vascular beds.

Hypotension induced by either KRN2391 or nicardipine was not associated with changes in HR. It has been demonstrated that nicardipine caused an increase in HR in alert humans which was mediated by a reflex sympathetic stimulation as a consequence of the decreased arterial blood pressure. ${ }^{15,16}$ Moreover, Bernard et al. ${ }^{8}$ reported that reflex tachycardia occurred in patients anaesthetized with fentanyl during nicardipine-induced hypotension. Similar to nicardipine, it has been reported that administration of KRN2391 (3-30 $\left.\mu \mathrm{g} \cdot \mathrm{kg}^{-1}\right)$ produced a dose-dependent decrease in blood pressure associated with an increase in $\mathrm{HR}$ in pentobarbital anaesthetized dogs. This increase in $\mathrm{HR}$ elicited by KRN2391 is inhibited by the $B$-adrenergic blocker (propranolol),${ }^{17}$ suggesting that the tachycardia was mediated by a reflex sympathetic activation. In contrast, the tachycardiac properties of either KRN2391 or nicardipine were blunted in the presence of isoflurane even though MAP decreased. It has been reported that reflex tachycardia did not occur during nicardipine-induced hypotension in halothane anaesthetized $\operatorname{dogs}^{18}$ or in patients anaesthetized with isoflurane. ${ }^{9}$ These differing results may have been due to the choice of anaesthesia. Seagard et al. 19,20 demonstrated that halothane and isoflurane block the baroreflex pathways, centrally and peripherally. Therefore, it is possible that the suppression of the baroreflexes due to the volatile anaesthetics on the heart could counteract the tachycardiac properties of KRN2391 and nicardipine. In addition, Hysing et al.21 reported that the interactions between nicardipine and isoflurane are mainly the result of the isoflurane-induced inhibition of reflex tachycardia elicited by nicardipine.

There were haemodynamic differences of SVR between KRN239I and nicardipine after drug discontinuation. We observed prolonged hypotension after the nicardipine-induced hypotension which is in agreement with the findings of Bernard $e t a l l^{8,9}$ and Takeda $e t a l{ }^{18}$ who reported prolonged hypotension after the infusion of nicardipine had been terminated. Our results demonstrated that nicardipine resulted in less evanescent effect than KRN2391, and suggested that KRN2391 may be more useful than nicardipine in clinical use. 
In conclusion, our results showed that the haemodynamic profile of KRN2391- and nicardipineinduced hypotension produced a hyperdynamic state expressed by an increase in CI with varying change in right and left ventricular filling pressures, and it is suggested that KRN239l may be a useful vasodilator for induced hypotension because of prompt recovery from hypotension.

\section{Acknowledgment}

The authors gratefully thank Yoshie Hirakawa for her excellent secretarial assistance. KRN2391 provided by the Kirin Brewery Co., Ltd. (Tokyo, Japan) was used for this study.

\section{References}

I Kashiwabara T, Nakajima S, Izawa T, Fukushima $H$, Nishikori $K$. Characteristics of KRN2391, a novel vasodilator, compared with those of cromakalim, pinacidil and nifedipine in rat aorta. Eur J Pharmacol $1991 ; 196: 1-7$.

2 Ishibashi $T$, Hamaguchi $M$, Imai $S$. Vasodilating properties of KRN2391: structural basis of a new pyridinetype potassium channel opener with a nitrate moiety. Naunyn-Schmiedeberg's Arch Pharmacol 1992; 346: 94-101.

3 Kashiwabara $T$, Ogawa N, Izawa T, Fukushima $H$. Differential vasodilator properties of KRN2391, cromakalim, nitroglycerin and nifedipine in rabbit isolated femoral artery and vein. $\mathrm{Br} \mathrm{J}$ Pharmacol 1994; 111: 278-82.

4 Ogawa $N$, Fukata $Y$, Kaneta S, Jinno $\Upsilon$, Fukusbima $H$, Nishikori K. Comparison of KRN2391 with nicorandil and nifedipine on canine coronary blood flow: antagonism by glibenclamide. J Cardiovasc Pharmacol 1992; 20: 11-7.

5 Ogawa N, Kaneta S, Jinno $\Upsilon$, Kasai H, Nishikori K, Fukushima $H$. Comparative cardiovascular effects of KRN2391 and other coronary vasodilators in anesthetized open-chest dogs. Arch Int Pharmacodyn 1992; 318 : 36-46.

6 Takeda $S$, Inada $\Upsilon$, Ozawa $\Upsilon$, Nakamizo N, Tomaru $T$. Hemodynamic effects of KRN2391 (potassium channel opener) in halothane-anesthetized dogs. J Anesth 1995; 9: 176-81.

7 Turlapaty $P$, Vary $R$, Kaplan JA. Nicardipine, a new intravenous calcium antagonist: a review of its pharmacology, pharmacokinetics, and perioperative applications. J Cardiothorac Anesth 1989; 3: 344-55.

8 Bernard J-M, Pinaud $M$, François $T$, Babin $M$, Macquin-Mavier I, Letenneur J. Deliberate hypotension with nicardipine or nitroprusside during total hip arthroplasty. Anesth Analg 1991; 73: 341-5.
9 Bernard J-M, Passuti N, Pinaud M. Long-term hypotensive technique with nicardipine and nitroprusside during isoflurane anesthesia for spinal surgery. Anesth Analg 1992; 75: 179-85.

10 Cook NS. The pharmacology of potassium channels and their therapeutic potential. Trends Pharmacol Sci 1988; 9: 21-8.

11 Lagerkranser $M$, Gordon $E$, Rudebill A. Cardiovascular effects of sodium nitroprusside in cerebral aneurysm surgery. Acta Anaesthesiol Scand 1980; 24: 426-32.

12 Lagerkranser $M$. Cardiovascular effects of nitroglycerin as a hypotensive agent in cerebral aneurysm surgery. Acta Anaesthesiol Scand 1982; 26: 453-7.

13 Takeda $S$, Inada $Y$, Tashiro $N$, et al. Endocrine effects of hypotension induced by nicardipine in rabbits. (Japanese) Masui 1990; 39: 971-7.

14 Takeda S, Inada $Y$, Nakamizo $N$, et al. A comparison of the endocrine effects of hypotension induced by nicardipine with those by sodium nitroprusside in dogs. (Japanese) Masui 1991; 40: 1063-9.

15 Toung MA, Watson RDS, Littler WA. Baroreflex setting and sensitivity after acute and chronic nicardipine therapy. Clin Sci 1984; 66: 233-5.

16 Lambert $C R$, Hill JA, Nichols WW, Feldman $R L$, Pepine $C J$. Coronary and systemic hemodynamic effects of nicardipine. Am J Cardiol 1985; 55: 652-6.

17 Takeuchi A, Harada K, Miwa A, et al. Effect of KRN2391 on canine ventricular arrhythmia models. Gen Pharmacol 1994; 25: 53-60.

18 Takeda S, Inada $Y$, Tashiro $N$, et al. Hemodynamic features of hypotension induced by nicardipine in dogs. (Japanese) Masui 1990; 39: 1586-96.

19 Seagard JL, Hopp FA, Donegan JH, Kalbfleisch JH, Kampine JP. Halothane and the carotid sinus reflex: evidence for multiple sites of action. Anesthesiology 1982; 57: 191-202.

20 Seagard JL, Elegbe EO, Hopp $F A$, et al. Effects of isoflurane on the baroreceptor reflex. Anesthesiology 1983; 59: 511-20.

21 Hysing ES, Chelly JE, Doursout M-F, Hartley C, Merin $R G$. Cardiovascular effects of and interaction between calcium blocking drugs and anesthetics in chronically instrumented dogs. III. Nicardipine and isoflurane. Anesthesiology 1986; 65: 385-91 